\title{
Polarization, Inequality, and the State Legislatures
}

\author{
David A. May ${ }^{1} \&$ Kevin A. Pirch ${ }^{1}$ \\ ${ }^{1}$ Department of Political Science, Eastern Washington University, Cheney WA USA \\ Correspondence: David A. May, Department of Political Science, Eastern Washington University, Cheney WA \\ 99004 USA. Tel: 1-509-359-2412. E-mail: dmay@ewu.edu
}

Received: March 26, 2016 Accepted: April 27, 2016 Online Published: May 29, 2016

doi:10.5539/jpl.v9n4p115 URL: http://dx.doi.org/10.5539/jpl.v9n4p115

\begin{abstract}
While legislative polarization at the national level has been carefully examined and largely explained, the causes of polarization in state legislatures have been more elusive. Studies examining factors such as gerrymandering and party primaries as possible explanations have found largely undetectable or at best very modest relationships between these variables and levels of polarization. This paper provides an explanation of state legislative polarization based on socio-economic and demographic factors within the states. Economics and demographics have long played a significant role in understanding party choice, vote choice, the decision to abstain or vote, and support for various policies. Because of this we explore if these factors also influence polarization of state legislatures. Utilizing the Shorr-McCarty polarization data for state legislatures, which provides the differences between the mean Democratic and Republican legislator scores, and controlling for important economic and demographic factors, we explain a significant amount of the polarization existing in state legislatures. These findings present a fascinating look into not only the root causes of polarization in state legislatures, but also point to some fundamental differences in politics and ideology at the state and national levels.
\end{abstract}

Keywords: polarization, state legislatures, inequality

\section{Introduction}

It has become a commonly accepted article of faith that there has been an increasing level of polarization between the two major political parties at both the state and national level over the past generation. With an increasing level of data and better measurement tools, political scientists have found that the $113^{\text {th }}$ Congress (2013-2015) was the most polarized Congress since Reconstruction. Most likely because of this, the $113^{\text {th }}$ Congress also was among the least productive in Congressional history, with only 296 laws passed compared to an average of 564 laws in the previous 20 Congresses (Cilliza, 2014; www.GovTrack.us, ND; Poole \& Rosenthal, ND). Of these laws passed, approximately 20 percent concerned naming government facilities such as post offices or hospitals, while many others concerned relatively non-controversial subjects such as appointing regents to the Smithsonian or the size of coins to be produced by the Baseball Hall of Fame (GovTrack.us, ND).

This ideological rift between the parties also has been blamed for the seeming inability of the legislative branch to pass substantive legislation regarding numerous important issues including debates about national security and civil liberties, the environment, gun control policy, and a host of other issues. In addition during this time of increased congressional polarization, the nation has seen the two political parties begin using a tactic of brinkmanship even for legislative actions which previously were considered essential and as a result passed relatively easily; actions such as votes on increasing the debt ceiling or funding of the government, which in the past were used as political cudgel but passed easily, now have become events which have roiled markets and panicked voters. In short, the Congress is reaching a state of debilitating paralyses not seen in more than 100 years (Mann \& Ornstein, 2008; Mann \& Ornstein, 2012).

\section{Explanations for the Polarization}

As this polarization has played out at the national level, political scientists have begun to question the extent of polarization in state legislatures and its potential causes. Most studies in the United States have tended to focus political institutions and actions, as well as changes in American culture as the primary causes or potential explanations for polarization of U.S. state legislatures. Among these rationales are the mechanisms for nominating candidates for office, the process of redistricting legislative boundaries, and changes in the ideologies and partisan sorting on the American electorate. 


\subsection{Party Primaries and Polarization}

One of the most common explanations for this polarization among media commentators, the public, and scholars is the idea that how candidates are nominated by their political parties determines how polarized the legislative body will become. In short, the modern system of primary nominations creates more polarized parties and elected officials. In theory, this causal explanation is rather simple: in states with closed primary systems where only declared party members can participate, only the most extreme partisans will vote. This polarization in the participants causes the two major parties to nominate their most politically extreme potential candidates for the general election. This ensures that those candidates who are elected will be on the extremes of the ideological spectrum creating a highly polarized legislative body (Downs, 1957). This theory is predicated upon two unique assumptions. The first is that there is a distinct difference between those people who vote in primaries (who tend to be more extreme in their views) compared to moderate general election voters, and second, that certain institutional rules in deciding the type of primary conducted influence those voters' choices to participate.

Generally speaking, in the academic literature, there is little to support the latter assumption and much debate about the former. Using data from the 2006 Cooperative Congressional Election Study (CCES), Abramowitz found very little ideological differences between primary voters and general election voters. Simply, Democratic voters and Republican voters are ideologically different from one another, but Democratic primary voters were only four percentage points more liberal than general election voters on an ideological scale and Republican primary voters only one percent more conservative (Abramowitz, 2008). Likewise, four years later using 2010 CCES data, Jacobson also found a bimodal distribution among the American electorate, with Democratic voters taking opposing views on a host of issues compared to Republicans and that party elites are only marginally more extreme than regular party members (Jacobson, 2012).

Other researchers have reached similar conclusions. Using data originally developed by Shor and McCarty (Shor \& McCarty, 2011), McGee et al found little evidence to support the theory that primary types play an important role in polarization of legislatures (McGhee, Masket, Shor, Rogers, \& McCarty, 2014). Moreover, the evidence found goes against the conventional wisdom, finding that rather than moderating candidates open primaries create more extreme partisans (Ibid). Additionally, the authors find that much of the causes of polarization remained unexplained in their model: "(the) most robust finding is that unexplained differences between the states absorb a large share of the variance in legislator ideology - at least one-third regardless of the model or specification. Whether this represents states' political economy, political culture, demographics, or other political institutions it seems safe to say that primary elections are not among the most important factors" (Ibid, 347).

\subsection{Redistricting and Polarization}

Like the description of party primaries as a cause of polarization of legislative bodies, the explanation that the process of redistricting legislative boundaries is relatively simple in theory. Here proponents claim that in states where elected partisans are allowed to draw the legislative district lines, those actors have strong incentives to draw their boundaries to their own benefit. Because of this, partisan redistricting systems create more electorally lopsided or highly gerrymandered districts, causing a large number of "safe seats." In these non-competitive districts, elected officials major concern is falling out of favor with their own party members rather than crafting positions that will allow reelection. Because of this, elected officials become more extreme in their positions causing more polarization in the legislative body. However intellectually elegant as this model is, the research finds that redistricting systems have a minimal if any effect on polarization and that any even modest effect may be at best short lived (Masket, Winburn, \& Wright, 2012).

While there are some metrics which are used to measure polarization in legislative bodies, there also are proxies that have become commonly accepted including the number of contested elections and the number of competitive races. These are often considered acceptable because they fit nicely into a theoretical explanation that less competitive elections lead to more polarization in the legislature. Evidence demonstrates that in states where the redistricting process is controlled by a bipartisan commission, there is an increasing likelihood that there would be more competitive races, however, there does not appear to be any other differences between partisan legislative redistricting and more bipartisan systems (Masket, Winburn, \& Wright, 2012). Other researchers note that polarization has been increasing across the nation regardless of the type of redistricting process. However, redistricting focusing on population based principles such as protecting communities of interest, the core of previous districts and some type of compactness all increase contested elections, while specifically protecting incumbents is likely to promote uncontested races and large margins of victory (Forgette, Garner, \& Winkle, 2009). 
Others have found some evidence that redistricting does play a qualified role in the increased levels of partisan polarization in the US House of Representatives. Noting that polarization levels have been higher in the House, which can be gerrymandered, compared to the Senate which is ungerrymanderable, Carson et al. found that congressional districts which have been significantly altered due to the redistricting process tend to be more extreme even after controlling for how safe the seat is and electoral replacement rates (Carson, Crespin, Finocchiaro, \& Rohde, 2007). However, some of what might be captured in measuring the effects of gerrymandering could actually be a result of Americans following a trend of living near other like-minded partisans (Bishop, 2008). If this is the case, than redistricting is merely a relatively accurate reflection of the geographic political realities of a community, rather than a desire to manipulate the redistricting process for political gain. Similarly, Abramowitz, Alexander and Gunning found redistricting was not the cause of polarization of legislative bodies, rather it was driven by changes in the American electorate and the power of incumbency (Abramowitz, Alexander, \& Gunning, 2006).

\subsection{A Partisan Sorting and Polarization}

Because there is minimal data supporting the idea that party primaries or redistricting are encouraging more polarized candidates, other scholars have proposed that polarization is a function of the party elites who have become more polarized. In this theory it is the elected officials, mass media, and other party elites who are becoming more extreme in their view. However, while this is occurring, simultaneously, what is being observed among non-elites is more akin to sorting as conservative Democrats moved to the Republican party and liberal Republicans became Democrats (Fiorina, 2006; Fiorina \& Levendusky 2006; Levendusky, 2009). In this theory, the political ideologies of average citizens remain constant but they are choosing to affiliate with political parties which are more reflective of their values. So, for example, there might have been little ideological change among the average Southern voter over the past few generations, it is just that those voters have left the Democratic Party and joined the Republicans. Because of this, the parties have in fact become more ideological distinct but only because voters are selecting parties based on ideology rather than other factors such as geography, religion, or historical affinity. The polarization in American society, simply put, is actually more of a homogenization of the political parties

\section{Method}

Polarization of legislative bodies in neither a new phenomena in the United States, nor is it one that has remained entirely unexplored. However, most of these studies have focused upon institutional or structural problems which could lead to creating a more polarized body. Others tend to focus on the dynamics of the American public, arguing in an unsettled debate that the body politic has changed in recent years and that a polarized legislature is accurately reflecting an increasingly polarized public. Rather than looking at revisiting these issues, we look instead at several socioeconomic differences in the 50 states to determine if there is something else driving the variations in polarization in state legislatures using OLS multivariate regression analysis.

\subsection{Data and Methods}

To measure this we use the Shor-McCarty Individual State Legislator Ideology Data as the basis for the independent variable. Based on Shor-McCarty's work, this data set examines the ideal ideological point of individual legislators from each of the 50 states over more than 15 years (Shor \& McCarthy, 2011). To measure the actual levels of polarization of the state legislators, we found the difference between the median Democratic legislator and median Republican legislator in each state for that particular year. The larger the difference between the two medians, the more polarized the state legislature is. We selected the years $2013^{1}$ and 2006 for this study to insure that the increased political pressures of a presidential election did not influence the legislative environment and to determine if the effects of the Great Recession had any impact on polarization in the states.

For dependent variables, an array of traditional economic and demographic factors that have long been understood to be critical factors of other aspects of American political life including party choice, the decision to vote or abstain and candidate preference, and support for various public policies were chosen. Because of this connection of socioeconomic indicators to so many aspects of U.S. political life it seems entirely reasonable that these indicators could also influence how far apart the major parties are from one another on the political spectrum. Among these were measures of partisan strength and party control of the legislatures and whether the state had term limits to examine the political climate of the state legislature. In addition, we looked at the

\footnotetext{
${ }^{1}$ Polarization scores were missing from five states in 2013, to account for this we used a pooled multiple imputation to correct for those variables.
} 
socioeconomic condition of the state using measures of the states' unemployment rates, educational attainment, levels of poverty, percentage of non-citizens, and levels on income inequality.

While no research of this type has yet been done at the state level, if these finding correspond with what is known about polarization on the national level, we should expect to see certain results. First, increased levels of income inequality at the national level has been correlated with increased levels of polarization and smaller majorities in the legislature should also lead to more polarization as the parties have incentives to remain united (McCarty, Poole \& Rosenthal 2006; Theriault, 2008; Riker, 1962; Garand, 2010).

\subsection{Statistics and Data Analysis}

Above all other findings it is clear that levels of income inequality have a major and statistically significant impact on the levels of polarization in state legislatures during both 2006 and 2013. In both cases, higher levels of income inequality lead to lower levels of political polarization. In addition, in 2006, the size of the majority party's control of the legislative body also has a depolarizing effect on the legislature. As the dominant party begins to control a larger percentage of the seats, there is a smaller distance between the median positions of the parties.

Table 1. State legislative polarization in 2006 and 2013

\begin{tabular}{lll}
\hline Variables & 2006 & 2013 \\
\hline Constant & $7.274 \dagger$ & $4.486^{*}$ \\
& $(1.563)$ & $(1.861)$ \\
Majority Party's Percent Control of & $-0.021^{* *}$ & -0.005 \\
Legislature & $(0.006)$ & $(0.004)$ \\
Income Inequality & $-14.575 \dagger$ & $-17.275^{* *}$ \\
& $(3.951)$ & $(5.309)$ \\
Percent of households below the Poverty Line & 0.061 & $0.148 \dagger$ \\
& $(0.033)$ & $(0.041)$ \\
Percent of population unemployed & -0.019 & 0.000 \\
& $(0.011)$ & $(0.060)$ \\
Percent of adults who are & 0.024 & $0.100 \dagger$ \\
college graduates & $(0.017)$ & $(0.025)$ \\
State's with term limits & $0.284^{*}$ & $0.310^{*}$ \\
& $(0.117)$ & $(0.150)$ \\
Percent of population not U.S. & $0.074 \dagger$ & 0.031 \\
Citizens & $(0.016)$ & $(0.025)$ \\
Republican control of legislature & 0.139 & 0.133 \\
& $(0.110)$ & $(0.170)$ \\
\hline *p $>0.05$ ** $\mathrm{p}>0.01 \dagger \mathrm{p}>0.001$ & $\mathrm{R} 2=0.556$ & \\
Standard deviations in parenthesis & &
\end{tabular}

However, there also are forces which are pulling to two parties further apart in 2006. During this time, states with term limits were more likely to be polarized than states without term limits and states with larger percentages of non-U.S. citizens also experienced increased levels of polarization. This model appears relatively robust with an $r^{2}=0.556$.

In 2013, many similar characteristics appear in the model. Like 2006, the overwhelming variable in explaining polarization in state legislatures was the level of income inequality, which becomes even more powerful than it was six years previously. Additionally, like 2006, states with term limits were more likely to be polarized than states without term limits. However, the number of non U.S. citizens as a predictive variable was replaced with the percent of households living below the poverty line and the percentage of the adult population with college 
degrees in explaining increased levels of polarization. Like, 2006, this model has a robust explanatory power with an $\mathrm{r}^{2}=0.410$.

2006

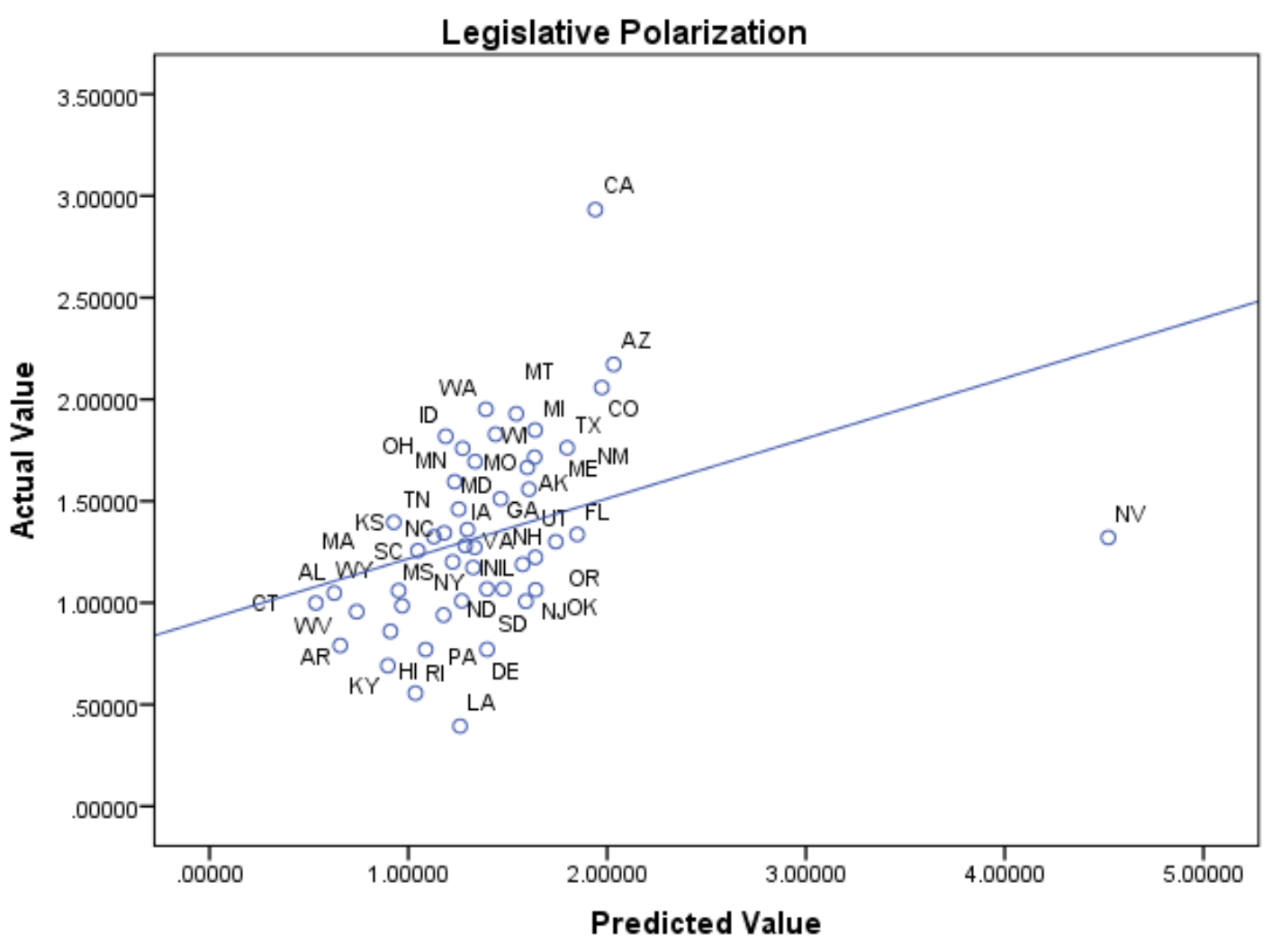

Figure 1.

The scatterplot for the 2006 data demonstrates again the strong relationship between the independent and dependent variables. While the line appears to the eye to be more flat than the data would suggest, it is important to note the presence of two significant outliers in an otherwise tightly clustered plot. The two obvious outliers are California and Nevada and neither is entirely surprising as an outlier. It has long been understood that California is an exception to many of the political realities of the other states. As far back as 1949 Carey McWilliams was able to write extensively on the unique nature of Californian culture and politics (1949). That it continues to be a nearly unique state with respect to politics is amply demonstrated later by Peter Schrag (1998). And so, California can be understood to be a true outlier in both the 2006 and 2013 data. In the 2006 data, the other significant outlier is Nevada and that is harder to explain within the literature. Speculative reasons for its outlier status might include a reaction to the incredibly rapid population growth that the state experienced throughout the 2000s, a continued "hangover" from some intensely partisan budget battles that began in 2003 and whose reverberations were still being felt in 2006 , or a reaction to larger politically polarizing events at the national level such as Harry Reid becoming the majority leader of the senate and engaging in sometimes intemperate statement about then President Bush and the state of the war effort in Iraq. 


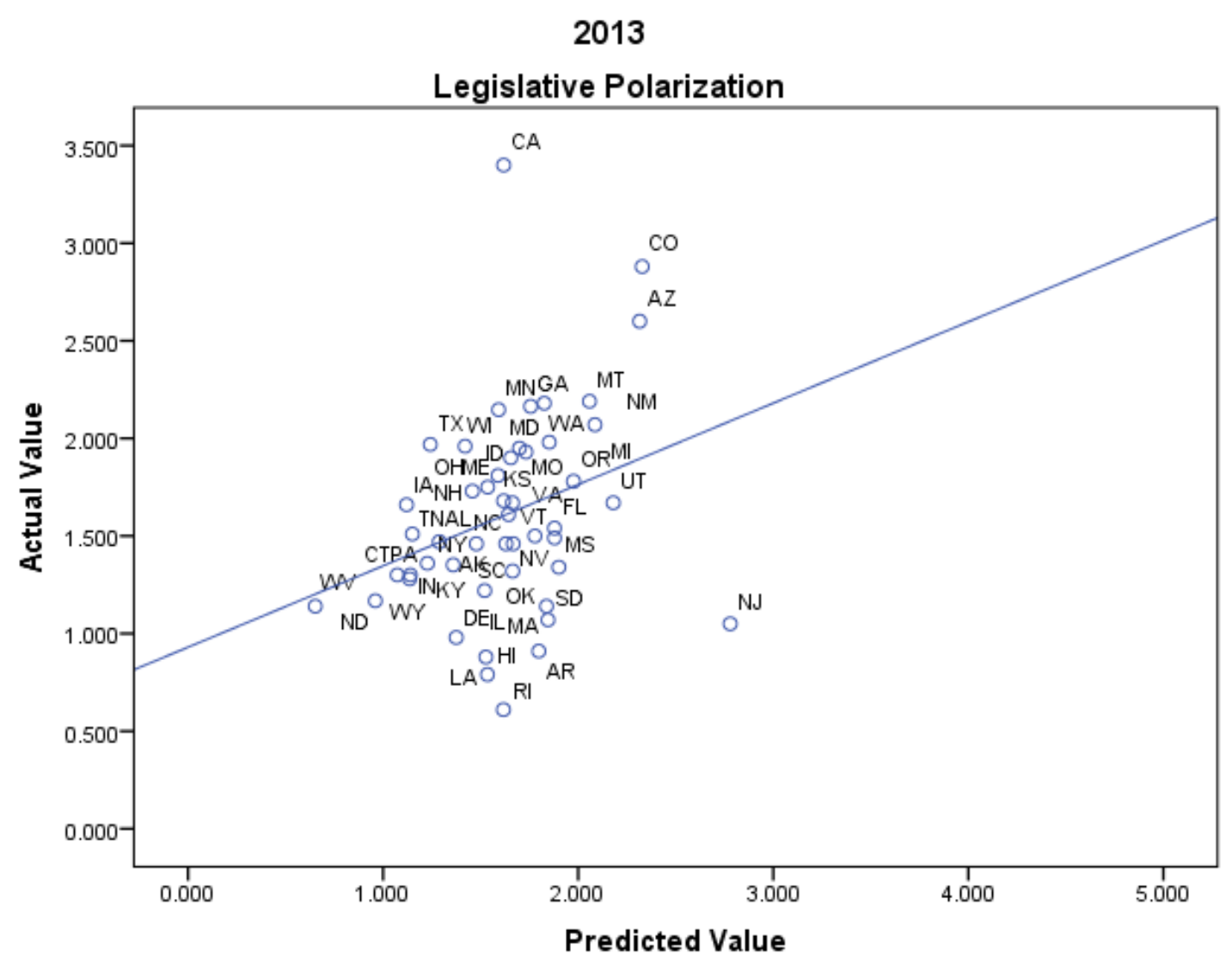

Figure 2.

As with 2006, the 2013 scatterplot shows a tightly constructed plot with, again, two significant outliers. Once again, California, for reasons stated above is not a surprising outlier although its distance from the fit line has increased. The other significant outlier in 2013 is the state of New Jersey. Speculative reasons for this reality include the fact that 2013 was a highly contested gubernatorial election year in the state with seven candidates vying to unseat the incumbent, Chris Christie. This election coincided with the fact that one of New Jersey's US Senator's, Frank Lautenberg, had died and the governor had called a special election to fill the vacancy. That call for a special election created significant controversy in the state when Governor Christie announced that the special election would be held three weeks before the general election. At a cost of over $\$ 12$ million, the decision was widely criticized as a partisan judgment to avoid having Democratic nominee Corey Booker on the same ticket as Christie in an effort to avoid increased minority turnout that might vote for Christie's opponent.

The statistical results as well as the scatter plots point to a very robust model that offers significant explanatory power. The presence of some outliers in the model is explainable by outside local and national political factors and those outliers do not appear to markedly diminish the efficacy of the model overall.

\section{Discussion}

Overshadowing all of the other findings in this model is the role which income inequality plays in the polarization of state legislatures and its two unique attributes: the size of the coefficient and its direction, both of which were unexpected according to previous research. While it has been well understood that increased levels of income inequality at the national level are a primary driver of polarization between the two major parties; at the state level the opposite is true.

Some of the findings of this model are reconfirmations of other research on polarization. Increased levels of non-U.S. citizens and people living in poverty are often seen as "wedge" issues which divide partisans both in the electorate and in legislatures. In fact, in regard to domestic policy, a focus on the wedge issues is often the raison d'etre of both the Democratic and Republican parties. These issues often include immigration and social safety net policies specifically designed for people living in poverty. So, increased numbers of non-U.S. citizens 
and low income families should reasonably be found pulling the two major parties apart on the ideological spectrum as those groups become more salient to policy debates. It is additionally intuitively appealing that the percent of the population which are non-U.S. citizens should be more significant in 2006 than in 2013, while poverty becomes a more important issue in 2013. Prior to the Great Recession, with low levels of unemployment and growing global economy, immigration issues had become a primary concern across the nation as migrants and undocumented workers were often characterized as taking American jobs. The Pew Research Center reported in 2006 an relatively even split between those who viewed immigrants as a source of "strength" (41 per cent) and those who viewed immigrants less favorably as a "burden" (52 per cent) (Smith, 2006). A 2006 Quinnipiac poll found that 88 per cent of respondents thought that illegal immigration represented either a "very serious" or "somewhat serious" problem (Quinnipiac University, 2006). However, as a result of the economic downturn and the increased numbers of non-citizens returning to their country of origin and the total number of unauthorized immigrants fall by eight percent between its peak in 2007 and 2010, immigration became a less compelling economic and political issue (Hoefer, Rytina, \& Baker, 2011). By 2013, the question of immigration had fallen to $17^{\text {th }}$ on the list of public priorities for the President and the Congress and, "just $44 \%$ of Republicans view[ed] illegal immigration as a top priority, down from $69 \%$ in 2007 and $61 \%$ as recently as [2011]" (Pew Research, 2013a). As a result of the recession, that concern was replaced by debates about the utility of other economic assistance programs, particularly those targeting people living in poverty.

In addition, while it appears that pure partisanship is not a predictor of polarization, with states clearly controlled only by Democrats or Republicans among the most and least polarized, the size of the majorities' control of the legislature does have some impact on polarization. This could be a product of two, non-mutually exclusive events. First, a larger majority would naturally produce a more diverse ideological body composed of some moderates and others who are more politically extreme. Because of this, it would not be surprising to find a larger majority to be more moderate and, therefore, less polarized than a smaller group of legislators. Additionally, a party which is barely holding on to their majority would probably be more cognizant of that fact and remain more unified than a larger body where individual members would feel less pressure to remain united. Likewise, it is understandable that states with term limits are more polarized than those without limits. Term limits prevent legislators from building personal trust through long term relationships and the creation of partnerships from shared experiences and time spent doing the people's business. Without these relationships, it is reasonable that members of the opposing parties would view each other more distrustfully.

However, overshadowing all of these findings is the role which income inequality plays in the polarization of state legislatures and its two unique attributes: the size of the coefficient and its direction, both of which were unexpected according to previous research. While it has been well understood that increased levels of income inequality at the national level are understood to be a primary driver of polarization between the two major parties; at the state level the opposite is true.

At the state level, increasing levels of inequality are associated with lower levels of polarization and we believe this is a product of the political debate and the framing of issues of income inequality and how those change between national and state level policymakers. At the national level, income inequality is seen as an ideological abstract which pits different ideologies and economic philosophies against one another. Simply, in Washington, D.C., income inequality is an abstract debate about ideas and ideal societies. However, in communities across the nation, income inequality produces profound problems which people expect their elected officials to address. At the state and local level, we believe income inequality is not seen as an abstract idea, but presents itself in more tangible ways. For example, income inequality would present itself as communities that are property poor and cannot afford quality public education, public universities and colleges with tuitions that have become increasingly unaffordable for middle class families, or families that cannot afford to live near work and require transportation and public infrastructure to commute longer distances. In these scenarios, state legislatures are then more likely to find a common ground solution to the problems of the middle class through levy equalization for school districts or transportation funding bills that invest in less populated areas. These problems are in addition to slightly more obvious examples of income inequality such as homelessness and un (or under) employment.

It should be noted that in 2006, neither the percentage of household below the poverty line nor percentage of the population that is unemployed were significantly related to the level of polarization. In 2013, the percentage of the population that lived below the poverty line was highly significant while the percentage of those unemployed remained insignificant. We believe this fits well with the general results of the model. Between 2006 and 2013 the ranks of those living below the poverty line were perceived increasingly as the deserving poor rather than the undeserving. The Pew Research Center reported in 2013 that, "65\% [of respondents] believed that most poor 
people in the U.S. do work but were unable to earn enough money" (Pew Research, 2013b). Our analysis suggests that, at the state level, short term solutions to the problem of poverty could be realized. Unemployment, however, could be viewed as a problem that has no state level solution and therefore remains insignificant as state legislators work to find middle ground.

It is then obvious why previous research has been unable to find a relationship between polarization and the structural features they have considered. It is important to note however that this common ground produced by decreases in polarization does not translate into specific policies or predict specific partisan outcomes - there is no statistical relationship between polarization scores and partisan electoral success, both parties can lay claim to both the least polarized and most polarized legislatures in the nation. What we argue is that when income inequality increases in a state, the two parties tend to find common ground in order to resolve identifiable, solvable, local problems.

In this explanation, state legislators might not even realize they are becoming less polarized and finding common ground because of higher levels of income inequality, rather they work to find solutions to discrete problems in the community. The ideological and philosophical differences that exist at the national level are not sustainable at the state level. At this level, solving problems of income inequality can be viewed by both parties as a commitment to strong communities or to the middle class rather than the ideologically difficult and divisive formulations of wealth redistribution or class warfare.

\section{References}

Abramowitz, A. (2008). Don't Blame Primary Voters for Polarization, The Forum, 5(4), 1-11. http://dx.doi.org/10.2202/1540-8884.1210

Abramowitz, A., Alexander, B., \& Gunning, M. (2006). Incumbency, Redistricting, and the Decline of Competition in U.S. House Elections. The Journal of Politics, 68(1), 75-88. http://dx.doi.org/10.1111/j.1468-2508.2006.00371.x

Bishop, B. (2008). The Big Sort: Why the Clustering of Like-Minded America is Tearing Us Apart. Boston: Houghton Mifflin.

Carson, J. L., Crespin, M. H., Finocchiaro C. J., \& Rohde, D. W. (2007). Redistricting and Party Polarization in the U.S. House of Representatives. American Politics Research, 35, 878-904. http://dx.doi.org/10.1177/1532673X07304263

Cizzila, C. (2014, February 4). How Congress Became the Most Polarized and Unproductive It's Ever Been. Washington Post. Retrieved from http://www.washingtonpost.com/blogs/the-fix/wp/2014/02/03/how-congress-became-the-most-polarized-an d-unproductive-its-ever-been/.

Downs, A. (1957). An Economic Theory of Democracy. New York: Harper Row.

Fiorina, M., \& Levendusky, M. (2006). Disconnected: The Political Class Versus the People. In Nivola, P. \& Brady, D. (Eds.), Red Blue Nation (Vol. 1, pp. 49-71). Washington, D.C.: The Brookings Institution.

Forgette, R., Garner, A., \& Winkle, J. (2009). Do Redistricting Principles and Practices Affect U.S. State Legislative Electoral Competition? State Politics \& Policy Quarterly, 9(2), 151-175. http://dx.doi.org/10.1177/153244000900900202

Garand, J. C. (2010). Income Inequality, Party Polarization, and Roll-Call Voting in the U.S. Senate. The Journal of Politics, 72(4), 1109-1128. http://dx.doi.org/10.1017/S0022381610000563

GovTrack.us Summary of Congressional Action. (2015). Retrieved March 18, 2015, from https://www.govtrack.us/congress/bills/browse?congress=113\&status $=28,29,32,33$

Hoefer, M., Rytina, N., \& Baker, B. C. (2011). Estimates of the Unauthorized Immigrant Population Residing in the United States: January 2010. Washington, DC: Office of Immigration Statistics, Department of Homeland Security.

Jacobson, G. C. (2012). The Electoral Origins of Polarized Politics: Evidence from the 2010 Cooperative Congressional Election Study. American Behavioral Scientist, 56(12), 1612-1630. http://dx.doi.org/10.1177/0002764212463352

Levendusky, M. (2009). The Partisan Sort: How Liberals Became Democrats and Conservatives Became Republicans. Chicago: University of Chicago Press. http://dx.doi.org/10.7208/chicago/9780226473673.001.0001 
Mann, T. E., \& Ornstein N. J. (2008). The Broken Branch: How Congress is Failing America and How to Get It Back on Track. New York: Oxford University Press.

Mann, T. E., \& Ornstein, N. J. (2012). It's Even Worse Than It Looks: How the American Constitutional System Collided with the New Politics of Extremism. New York: Basic Books.

Masket, S. E., Winburn, J., \& Wright, J. (2012). The Gerrymanderers Are Coming! Legislative Redistricting Won't Affect Competition or Polarization Much, No Matter Who Does It. PS: Political Science and Politics, 45(1), 39-43. http://dx.doi.org/10.1017/s1049096511001703

McCarty, N., Poole K. T., \& Rosenthal, H. (2006). Polarized America: The Dance of Ideology and Unequal Riches. Cambridge, MA: MIT Press.

McGhee, E., Masket, S. E., Shor, B., Rogers, S., \& McCarty, N. (2014). A Primary Cause of Partisanship? Nomination Systems and Legislator Ideology. American Journal of Political Science, 58(2), 337-351. http://dx.doi.org/10.1111/ajps.12070

McWilliams, C. (1949). California: The Great Exception. Berkeley and Los Angeles, CA: University of California Press.

Pew Research Center (2013a). Retrieved from http://www.pewresearch.org/2013/01/28/immigration-rises-on-washingtons-agenda-not-the-publics/

Pew Research Center. (2013b). Retrieved from http://www.pewresearch.org/fact-tank/2013/12/05/americans-see-growing-gap-between-rich-and-poor/

Poole, K., \& Rosenthal, H. (2015). Retrieved from http://www.voteview.com/political_polarization_2014.htm

Quinnipiac University. (2006). Illegal Immigration Worries Immigrant Descendants, Quinnipiac University National Poll Finds; Most U.S. Voters Say Cut Benefits. Retrieved from http://www.quinnipiac.edu/news-and-events/quinnipiac-university-poll/national/release-detail?ReleaseID=8 82

Riker, W. H. (1962). The Theory of Political Coalitions. New Haven, CT: Yale University Press.

Schrag, P. (1998). Paradise Lost: California's Experience, America's Future. Berkeley and Los Angeles, CA: University of California Press.

Shor, B., \& McCarty, N. (2011). The Ideological Mapping of American Legislatures. American Political Science Review, 105(3), 530-551. http://dx.doi.org/10.1017/S0003055411000153

Smith, G. A. (2006). Attitudes Towards Immigration: In the Pulpit and the Pew. Retrieved from http://www.pewresearch.org/2006/04/25/attitudes-toward-immigration-in-the-pulpit-and-the-pew/

Theriault, S. M. (2008). Party Polarization in Congress. New York: Cambridge. http://dx.doi.org/10.1017/CBO9780511790652

\section{Copyrights}

Copyright for this article is retained by the author(s), with first publication rights granted to the journal.

This is an open-access article distributed under the terms and conditions of the Creative Commons Attribution license (http://creativecommons.org/licenses/by/3.0/). 